\title{
Model for End Stage Liver Disease Clinical Classification
}

National Cancer Institute

\section{Source}

National Cancer Institute. Model for End Stage Liver Disease Clinical Classification. NCI

Thesaurus. Code C121008.

A standardized rating scale developed by Malinchoc et al in 2000, which is a classification system used to assess severity of chronic liver disease and to determine the urgency of a subject needing a liver transplant within the next three months. This instrument uses the values of serum bilirubin and creatinine, and the international normalized ratio for prothrombin time (INR) to predict survival for patients with advanced liver disease. 